\title{
Identifying women with gestational diabetes based on maternal characteristics: an analysis of four Norwegian prospective studies
}

Anam Shakil Rai ${ }^{1 *}$, Line Sletner ${ }^{2,3}$, Anne Karen Jenum ${ }^{4}$, Nina Cecilie Øverby ${ }^{5}$, Signe Nilssen Stafne ${ }^{6,7}$, Tove Lekva $^{8}$, Are Hugo Pripp ${ }^{9}$ and Linda Reme Sagedal ${ }^{1,10}$

\begin{abstract}
Background: There is still no worldwide agreement on the best diagnostic thresholds to define gestational diabetes (GDM) or the optimal approach for identifying women with GDM. Should all pregnant women perform an oral glucose tolerance test (OGTT) or can easily available maternal characteristics, such as age, BMI and ethnicity, indicate which women to test? The aim of this study was to assess the prevalence of GDM by three diagnostic criteria and the predictive accuracy of commonly used risk factors.

Methods: We merged data from four Norwegian cohorts (2002-2013), encompassing 2981 women with complete results from a universally offered OGTT. Prevalences were estimated based on the following diagnostic criteria: ${ }_{1999} \mathrm{WHO}$ (fasting plasma glucose (FPG) $\geq 7.0$ or 2 -h glucose $\geq 7.8 \mathrm{mmol} / \mathrm{L}$ ), $2013 \mathrm{WHO}$ (FPG $\geq 5.1$ or 2-h glucose $\geq 8.5$ $\mathrm{mmol} / \mathrm{L}$ ), and ${ }_{2017}$ Norwegian (FPG $\geq 5.3$ or 2 -h glucose $\geq 9 \mathrm{mmol} / \mathrm{L}$ ). Multiple logistic regression models examined associations between GDM and maternal factors. We applied the ${ }_{2013} \mathrm{WHO}$ and ${ }_{2017}$ Norwegian criteria to evaluate the performance of different thresholds of age and BMI.

Results: The prevalence of GDM was 10.7, 16.9 and 10.3\%, applying the ${ }_{1999} \mathrm{WHO},{ }_{2013} \mathrm{WHO}$, and the 2017 Norwegian criteria, respectively, but was higher for women with non-European background when compared to European women (14.5 vs $10.2 \%, 37.7$ vs $13.8 \%$ and 27.0 vs $7.8 \%$ ). While advancing age and elevated BMI increased the risk of GDM, no risk factors, isolated or in combination, could identify more than $80 \%$ of women with GDM by the latter two diagnostic criteria, unless at least $70-80 \%$ of women were offered an OGTT. Using the ${ }_{2017}$ Norwegian criteria, the combination "age $\geq 25$ years or BMI $\geq 25 \mathrm{~kg} / \mathrm{m}^{2}$ " achieved the highest sensitivity (96.5\%) with an OGT required for $93 \%$ of European women. The predictive accuracy of risk factors for identifying GDM was even lower for nonEuropean women.
\end{abstract}

\footnotetext{
* Correspondence: anamsr@uia.no

${ }^{1}$ Department of Research, Sorlandet Hospital, 4604 Kristiansand, Norway

Full list of author information is available at the end of the article
}

(c) The Author(s). 2021 Open Access This article is licensed under a Creative Commons Attribution 4.0 International License, which permits use, sharing, adaptation, distribution and reproduction in any medium or format, as long as you give appropriate credit to the original author(s) and the source, provide a link to the Creative Commons licence, and indicate if changes were made. The images or other third party material in this article are included in the article's Creative Commons licence, unless indicated otherwise in a credit line to the material. If material is not included in the article's Creative Commons licence and your intended use is not permitted by statutory regulation or exceeds the permitted use, you will need to obtain permission directly from the copyright holder. To view a copy of this licence, visit http://creativecommons.org/licenses/by/4.0/. The Creative Commons Public Domain Dedication waiver (http://creativecommons.org/publicdomain/zero/1.0/) applies to the data made available in this article, unless otherwise stated in a credit line to the data. 
Conclusions: The prevalence of GDM was similar using the ${ }_{1999} \mathrm{WHO}$ and ${ }_{2017}$ Norwegian criteria, but substantially higher with the ${ }_{2013} \mathrm{WHO}$ criteria, in particular for ethnic non-European women. Using clinical risk factors such as age and BMI is a poor pre-diagnostic screening method, as this approach failed to identify a substantial proportion of women with GDM unless at least $70-80 \%$ were tested.

Keywords: Gestational diabetes mellitus, Pre pregnancy BMI, Pregnancy, Screening, Diagnostic criteria

\section{Background}

Gestational diabetes mellitus (GDM) is glucose intolerance with onset or first diagnosis during pregnancy which is clearly not overt diabetes [1]. GDM is associated with higher maternal and neonatal morbidities in the short- and long-term and predisposes both women and their offspring to later development of type 2 diabetes [2]. Screening followed by treatment of GDM reduces the risk of several pregnancy complications [3]. However, there is no worldwide agreement on the best diagnostic thresholds to define GDM, and a wide variety of clinical guidelines have been employed [4].

In 2013, the World Health Organization (WHO) recommended glycaemic thresholds for the diagnosis of GDM based on findings from the multinational Hyperglycaemia and Adverse Pregnancy Outcome (HAPO) study demonstrating a linear dose-response between maternal glycaemia and adverse neonatal outcomes. These criteria were determined to identify women with an adjusted odds ratio (OR) of 1.75 for adverse events in their offspring relative to the mean [5]. Glucose values set to identify women with a higher risk, corresponding to an adjusted OR of 2.0, were also considered but this proposal was rejected. Nonetheless, several countries, among them Canada and Norway, adopted the latter noting the substantial rise in GDM prevalence by ${ }_{2013} \mathrm{WHO}$ criteria, without clear evidence of clinically important benefits [6]. The prior WHO criteria, established in 1999 and used in Norway until 2017, were identical to those for diagnosis of glucose intolerance in a non-pregnant population.

Controversy surrounds not only the thresholds values of glycemia, but also the optimal approach for identifying women with GDM. A high-risk approach has traditionally been recommended based on easily available maternal characteristics such as advanced age and BMI, known to be associated with an increased risk of GDM [7]. However, although this approach reduces unnecessary testing in those least likely to test positive, a key issue is their performance as indicators for diagnostic testing and the usefulness of risk factors in a clinical setting today [8]. The alternative option, universal screening, has a high detection rate but poses a large immediate burden to healthcare services as well as pregnant women.

In this study that merged data from four existing Norwegian pregnancy and birth cohorts, we aimed to address some of the clinical controversies related to GDM diagnosis and screening. The objectives were: 1) To establish the prevalence of GDM with three diagnostic criteria ${ }_{1999} \mathrm{WHO},{ }_{2013} \mathrm{WHO}$, and the ${ }_{2017}$ Norwegian criteria), 2) identify cut-off levels for age and BMI that identify at least $80 \%$ of women with GDM and 3) assess the predictive accuracy of commonly used risk factors.

\section{Methods}

All population-based birth cohort studies in Norway with a special focus on gestational diabetes were eligible. For the present study, the following inclusion criteria were defined: (i) prospective studies comprising women with singleton live-born children recruited early in pregnancy (between week 15-20); (ii) data on maternal pre-pregnancy BMI; (iii) glucose measurements obtained from at least one universally offered $75 \mathrm{~g}$ 2-h oral glucose tolerance test (OGTT) performed $\geq 20$ weeks' gestation; (iv) at least one offspring measurement (birthweight). Exclusion criteria were studies without the core data and studies that only included specific subgroups (such as obese women only).

Four Norwegian studies (two cohort studies ( [9, 10] and two randomized controlled trials (RCT) [11, 12] were identified, and primary investigators were invited to become part of the "Norwegian Hyperglycemia in pregnancy" consortium in 2017. Principal investigators from all four studies agreed to participate, providing data from 3315 pregnant women and 3293 live births (Fig. 1).

The original studies collected data between 2002 and 2013. If GDM was diagnosed, women received diabetes care according to local guidelines. Details of the methods and characteristics of participants in each study, including eligibility criteria, methods of recruitment and measurements obtained, have been previously published [9-12]. Authors were requested to provide anonymous raw data to be stored and analyzed in The University of Oslo's Service for Sensitive data (TSD) storage platform with access for all 


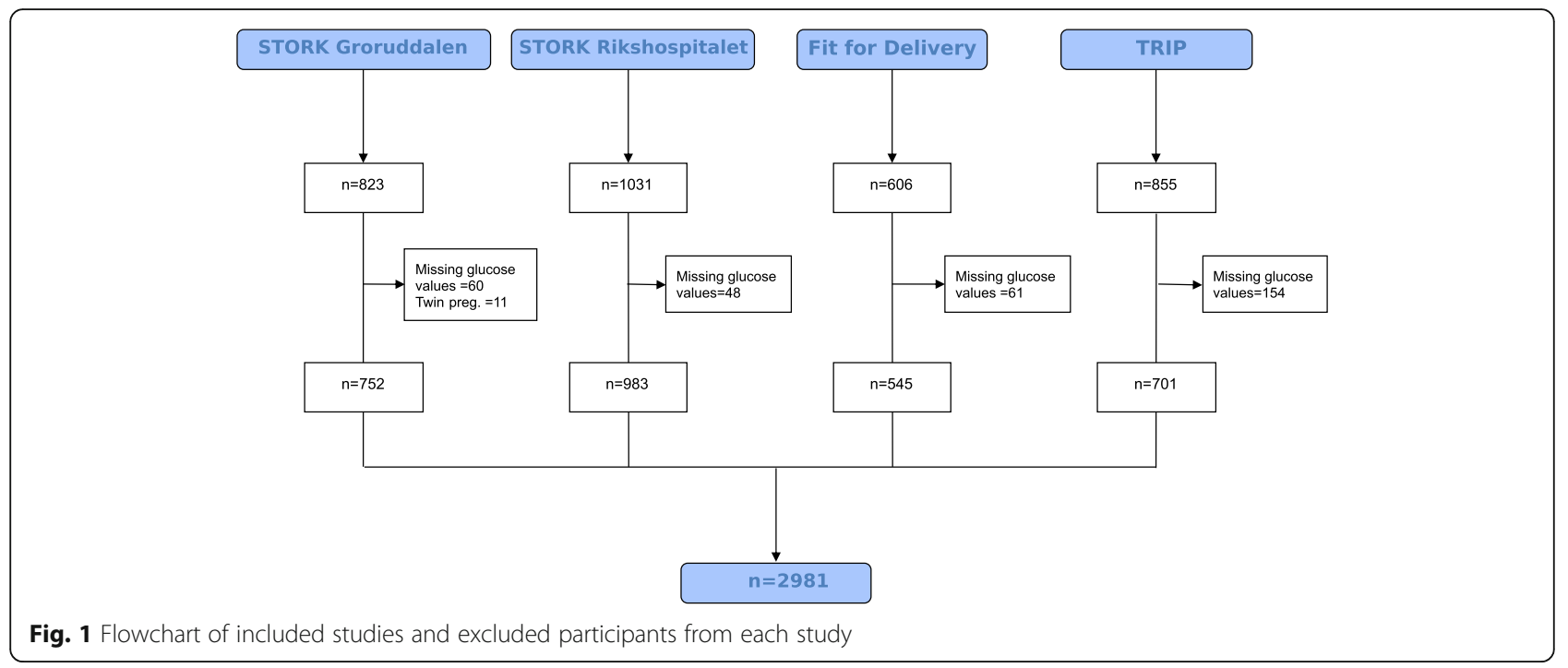

the project partners. Data were further harmonized and assessed for internal consistency and missing items. Investigators were asked for clarification on issues regarding the coding of variables and a final summary of relevant variables was sent for verification. After resolution, all datasets were merged. We excluded from analyses participants for which no OGTT data were available, as well as multi-fetal pregnancies (Fig. 1).

The primary outcome was GDM prevalence. All women underwent a $75 \mathrm{~g}$ OGTT after an overnight fast. In two of the studies $[9,10]$ venous blood samples were collected in tubes containing Ethylenediaminetetraacetic acid (EDTA) and glucose was analyzed on site in fresh, whole EDTA blood, using HemoCue 201+ glucose analyser (Angelholm, Sweden) [9] or a Accu-Chek Sensor glucometer (Roche Diagnostics, Mannheim, Germany) [10] according to protocols. In Sagedal et al. [11] and Stafne et al. [12] fasting and 2-h glucose levels were measured in plasma or serum, respectively, by the routine methods used at the participating hospital laboratory.

The diagnosis was originally made according to the ${ }_{1999}$ WHO criteria which was used during data collection. In addition, we applied the ${ }_{2013} \mathrm{WHO}$ criteria and the ${ }_{2017}$ Norwegian criteria (Table 1) for the purposes of this specific study. The ${ }_{2013}$ WHO criteria also includes a 1-h

Table 1 Criteria for gestational diabetes

\begin{tabular}{llll}
\hline Glucose value & ${ }_{1999}$ WHO & 2013 WHO & 2017 Norwegian \\
\hline Fasting & $\geq 7.0 \mathrm{mmol} / \mathrm{L}$ & $\geq 5.1 \mathrm{mmol} / \mathrm{L}$ & $\geq 5.3 \mathrm{mmol} / \mathrm{L}$ \\
2-h & $\geq 7.8 \mathrm{mmol} / \mathrm{L}$ & $\geq 8.5 \mathrm{mmol} / \mathrm{L}$ & $\geq 9.0 \mathrm{mmol} / \mathrm{L}$ \\
\hline
\end{tabular}

Based on a $75 \mathrm{~g}$ Oral Glucose Load. For the diagnosis, one or more of the glucose values must be met or exceeded glucose which was not measured in the respective studies.

In each individual study, women were either interviewed or asked to complete a questionnaire including information on current smoking status and their highest educational qualification. Women were further assessed at the study sites with respect to biological and anthropometric data. Height was measured directly while weight prior to becoming pregnant was self-reported in all studies. Categories for age and pre-pregnancy body mass index (BMI) were determined prior to analysis and based on clinical relevance. Furthermore, women were classified as primiparous or parous for the purpose of this study.

STORK Groruddalen [9] was the only study that actively included a multiethnic population (59\% ethnic minority women, primarily born outside Europe). Ethnic origin was defined as European (predominantly Scandinavian as well as East and West-European origin) or non-European (mainly Asian, North-African, Middle Eastern or Sub-Sahara African). Family history of diabetes was not measured in the Fit for Delivery study.

\section{Statistical analysis}

Distributions of all potential predictors were checked for normality. The characteristics of the women were categorized by GDM-status and the two groups were compared using $\mathrm{X}^{2}$ statistic for categorical data and the Student's t Test for continuous variables. Data are reported as frequencies and percentages for categorical variables and mean and standard deviation for continuous variables.

Information was available for $95 \%$ of the selected covariates. To assign values for the missing data for 
pre-pregnancy weight $(5 \%)$, height $(0.4 \%)$, educational attainment $(0.3 \%)$ and parity $(0.3 \%)$ we used Stochastic regression imputation with predictive mean matching as the imputation model to substitute missing items in the observed population [13].

To examine associations between GDM and maternal factors, we modelled GDM as a binary outcome (GDM vs no-GDM) and variables related to GDM in univariable logistic regression models with $p$-value $<0.2$ were considered in separate multivariable analyses [14]. The final model resulted from a backward selection procedure (exclusion if $p>0.15$ ). All models were adjusted for cohort to handle unmeasured confounders. Results from logistic regression are presented as OR with accompanied 95\% confidence intervals (CI), and with Nagelkerke $\mathrm{R}^{2}$ for model fit.

In the analyses, the two RCT's were treated as cohort studies as the primary outcome (GDM) did not differ between control and intervention group in the original studies $[11,12]$. The interventions in the two trials consisted of either an exercise program (supervised exercise sessions) or a combination of a physical activity component and dietary counselling. The regression analysis was repeated after excluding participants who received the intervention to examine the potential role of the intervention in these RCTs.

Finally, we assessed the diagnostic accuracy across different pre-specified cut-offs for maternal age and BMI with and without the addition of parity, based on previous and current screening guidelines. We calculated sensitivity (proportion of GDM cases correctly identified by the risk factor), specificity (proportion of women without GDM who did not have the risk factor), and the proportion of women with the risk factor (i.e. who would be offered an OGTT). Analyses were performed and presented separately for European and non-European women due to strong effect of ethnicity. For each risk factor, single or in combination, the sensitivity estimates were plotted in Receiver Operating Characteristic (ROC) space against the proportion of women subjected to OGTT. An optimal risk factor combination will have high sensitivity with small numbers needing to be tested (results near the top left of the space). We opted for a sensitivity level of $80 \%$ for the risk factors. Statistical analyses were performed using SPSS software, Version 26 (USA).

\section{Results}

We excluded more participants from the TRIP study than from the other studies due to missing GDM data (Fig. 1). Apart from this, no significant differences were noted between the women who were included in the study and those excluded (not shown). After exclusions, the pooled dataset comprised 2981 women with a mean (SD) age of 30.2 (4.4) years and pre-pregnant BMI of $23.7 \mathrm{~kg} / \mathrm{m}^{2}$ (Table 2). The majority were of European origin (87.0\%), had higher education (73.4\%) and were in their first pregnancy $(61.0 \%)$. GDM was diagnosed in 320 (10.7\%), $504(16.9 \%)$ and $308(10.3 \%)$ pregnancies with the ${ }_{1999} \mathrm{WHO},{ }_{2013} \mathrm{WHO}$ and ${ }_{2017}$ Norwegian criteria, respectively.

The prevalence rates in European women compared to non-European women were 10.2 vs $14.5 \%$, 13.8 vs $37.7 \%$ and 7.8 vs $27.0 \%$, applying the ${ }_{1999} \mathrm{WHO},{ }_{2013} \mathrm{WHO}$ and ${ }_{2017}$ Norwegian criteria, respectively (Fig. 2).

Compared with the non-GDM group, women diagnosed with GDM by either criteria were more likely to be older, heavier, shorter and of non-European origin (Supporting information Table S1, additional file 1). Moreover, using the ${ }_{2017}$ Norwegian criteria, while $25.5 \%$ of women without GDM had overweight or obesity (BMI $\left.>25 \mathrm{~kg} / \mathrm{m}^{2}\right)$, this was observed in $51.3 \%$ of women with GDM $(P<0.001)$. There were more primiparas in the non-GDM group $(P<0.001)$, except when applying the ${ }_{1999} \mathrm{WHO}$ criteria.

In logistic regression analyses, all selected variables except smoking, were significantly associated with GDM with the ${ }_{2017}$ Norwegian criteria prior to adjustments (Table 3). Nevertheless, the associations observed for parity, education and height were strongly attenuated and lost their significance in the multivariable adjusted model 1. Age, pre-pregnancy BMI and ethnicity remained the only significant predictors in the final multivariable model (model 2). However, compared with women $\leq 25$ years, an increased OR for developing GDM was only found for those above 35 years of age (aOR 1.73; 95\% CI: $1.07-2.80 ; P<0.026$ ).

Applying the ${ }_{2013} \mathrm{WHO}$ criteria led to similar findings (Table 4). For the ${ }_{1999} \mathrm{WHO}$, however, nonEuropean ethnicity was not significantly associated with GDM, while parity and height remained significant in the final adjusted model (Supporting information Table S2, additional file 1). The predictive power of all models was low, with Nagelkerke values ranging from 0.9 to $16.4 \%$, depending on the criteria applied. Sensitivity analysis restricted to individuals without lifestyle intervention in two of the cohorts led to similar findings, although age was no longer significant (not shown).

Table 5 displays estimates of sensitivity and the proportion needed to be screened for selected risk factors combinations, stratified for ethnic origin. In 
Table 2 Characteristics of the participating pregnancy and birth cohorts

\begin{tabular}{|c|c|c|c|c|c|}
\hline Characteristics & $\begin{array}{l}\text { Stork Grorudddalen } \\
n=752\end{array}$ & $\begin{array}{l}\text { Stork Rikshospitalet } \\
n=983\end{array}$ & $\begin{array}{l}\text { Fit for Delivery } \\
n=545\end{array}$ & $\begin{array}{l}\text { TRIP } \\
n=701\end{array}$ & $\begin{array}{l}\text { Total } \\
n=2981\end{array}$ \\
\hline Study period & 2008-2010 & $2002-2008$ & 2009-2013 & 2007-2009 & \\
\hline Type of study & cohort & cohort & $\mathrm{RCT}$ & $\mathrm{RCT}$ & \\
\hline Gest. age at inclusion (weeks) & $15.1 \pm 3.4$ & $15.8 \pm 1.3$ & $15.1 \pm 2.6$ & $20.2 \pm 1.6$ & $16.5 \pm 3.1$ \\
\hline Gest. age at OGTT (weeks) & $28.3 \pm 1.3$ & $31.2 \pm 1.0$ & $29.6 \pm 0.8$ & $34.0 \pm 2.0$ & $30.8 \pm 2.5$ \\
\hline European ethnicity & $363(48.3)$ & $983(100)$ & $541(99.3)$ & $701(100)$ & $2588(86.8)$ \\
\hline Current smoker & $31(5.0)$ & $23(2.3)$ & $20(3.7)$ & $6(0.9)$ & $80(2.8)$ \\
\hline \multicolumn{6}{|l|}{ Education } \\
\hline primary or less & $124(16.5)$ & $12(1.2)$ & $10(1.8)$ & $3(0.4)$ & $149(5.0)$ \\
\hline High school education & $297(39.5)$ & $128(13.0)$ & $158(29.0)$ & $62(8.8)$ & $645(21.6)$ \\
\hline Higher education & $331(44.0)$ & $843(85.8)$ & $377(69.2)$ & $636(90.7)$ & $2187(73.4)$ \\
\hline Primipara & $345(45.9)$ & $524(53.3)$ & $545(100)$ & $405(57.8)$ & $1819(61.0)$ \\
\hline Diabetes in family & $191(26.1)$ & $98(10.5)$ & NM & $61(9.1)$ & $350(11.7)$ \\
\hline \multicolumn{6}{|l|}{ Age (years) } \\
\hline Total & $29.9 \pm 4.8$ & $31.3 \pm 3.8$ & $28.0 \pm 4.3$ & $30.6 \pm 4.2$ & $30.2 \pm 4.4$ \\
\hline Primipara & $28.1 \pm 4.6$ & $30.0 \pm 3.7$ & $28.0 \pm 4.3$ & $29.2 \pm 3.7$ & $28.9 \pm 4.1$ \\
\hline Parous & $31.4 \pm 4.5$ & $32.7 \pm 3.6$ & a & $32.4 \pm 4.1$ & $32.2 \pm 4.0$ \\
\hline Prepregnant BMI (kg/m²) & $24.6 \pm 4.8$ & $23.4 \pm 3.7$ & $23.6 \pm 3.8$ & $23.1 \pm 3.1$ & $23.7 \pm 3.9$ \\
\hline BMI at inclusion $\left(\mathrm{kg} / \mathrm{m}^{2}\right)$ & $25.3 \pm 4.8$ & $24.5 \pm 3.4$ & $24.5 \pm 3.9$ & $24.7 \pm 3.1$ & $24.8 \pm 4.0$ \\
\hline Fasting glucose at OGTT (mmol/L) & $4.8 \pm 0.6$ & $4.6 \pm 0.4$ & $4.6 \pm 0.4$ & $4.3 \pm 0.4$ & $4.6 \pm 0.5$ \\
\hline 2-h glucose at OGTT (mmol/L) & $6.2 \pm 1.4$ & $6.2 \pm 1.4$ & $6.1 \pm 1.3$ & $5.7 \pm 1.2$ & $6.1 \pm 1.3$ \\
\hline GDM, ${ }_{1999}$ WHO-criteria & $97(12.9)$ & $124(12.6)$ & $57(10.5)$ & $42(6.0)$ & $320(10.7)$ \\
\hline GDM, 2013 WHO-criteria & $236(31.4)$ & $145(14.8)$ & $76(13.9)$ & $47(6.7)$ & $504(16.9)$ \\
\hline GDM, ${ }_{2017}$ Norway-criteria & $156(20.7)$ & $87(8.9)$ & $38(7.0)$ & $27(3.9)$ & $308(10.3)$ \\
\hline
\end{tabular}

Data presented as mean \pm SD or $\mathrm{n}(\%)$. Values are imputed for pre-pregnancy weight, parity and education

a Only primipara included in the study

OGT oral glucose tolerance test, BMI body mass index, GDM gestational diabetes mellitus, WHO World Health Organization, NM not measured

European women, the combination "age $\geq 25$ years or BMI $\geq 25 \mathrm{~kg} / \mathrm{m}^{2}$ " achieved the highest sensitivity of 96.5\% (i.e. detected $96.5 \%$ of GDM cases), but because these risk factors occurred in 93\%, an OGTT would be required in almost all women. By adding parity to the age thresholds (25 years for primipara and 35 years for parous) the number of OGTT needed was reduced to $75 \%$, although a reduction in sensitivity to $85 \%$ was observed. Similar trends were observed for women with non-European background, except that family history of diabetes achieved a higher sensitivity $(42.6 \%)$ than in their European counterparts (11\%). Overall, the sensitivity of the risk factors was slightly higher when applying the ${ }_{2017}$ Norwegian criteria than the ${ }_{2013}$ WHO.

Figure 3 shows the proportion of correctly identified GDM cases for European women, and proportion that would be offered an OGTT for each risk factor or combination of factors by the
${ }_{2017}$ Norwegian and ${ }_{2013} \mathrm{WHO}$ criteria. Irrespective of the risk factor used, the sensitivity increased with the number of women needing a test for both diagnostic criteria, displaying three clusters of four to five factors with poor, moderate and good performance. To identify at least $80 \%$ of women with GDM (good performance), at least $75 \%$ of all women would need to undergo an OGTT. The risk factor displaying both high sensitivity and the smallest proportion of OGTT's, was the combination "BMI $\geq 25$ $\mathrm{kg} / \mathrm{m}^{2}$ or (primipara+age $\geq 25$ ) or (parous+age $\geq 35$ )". With $75 \%$ requiring a test, this factor combination failed to identify $15 \%$ of women with GDM by ${ }_{2017}$ Norwegian criteria. The proportion of OGTT required could be reduced to $54 \%$ by increasing the threshold for age to $\geq 30$ years for primipara (moderate performance); however, this approach implies that $27 \%$ of women with GDM will remain undiagnosed (Table 5). 


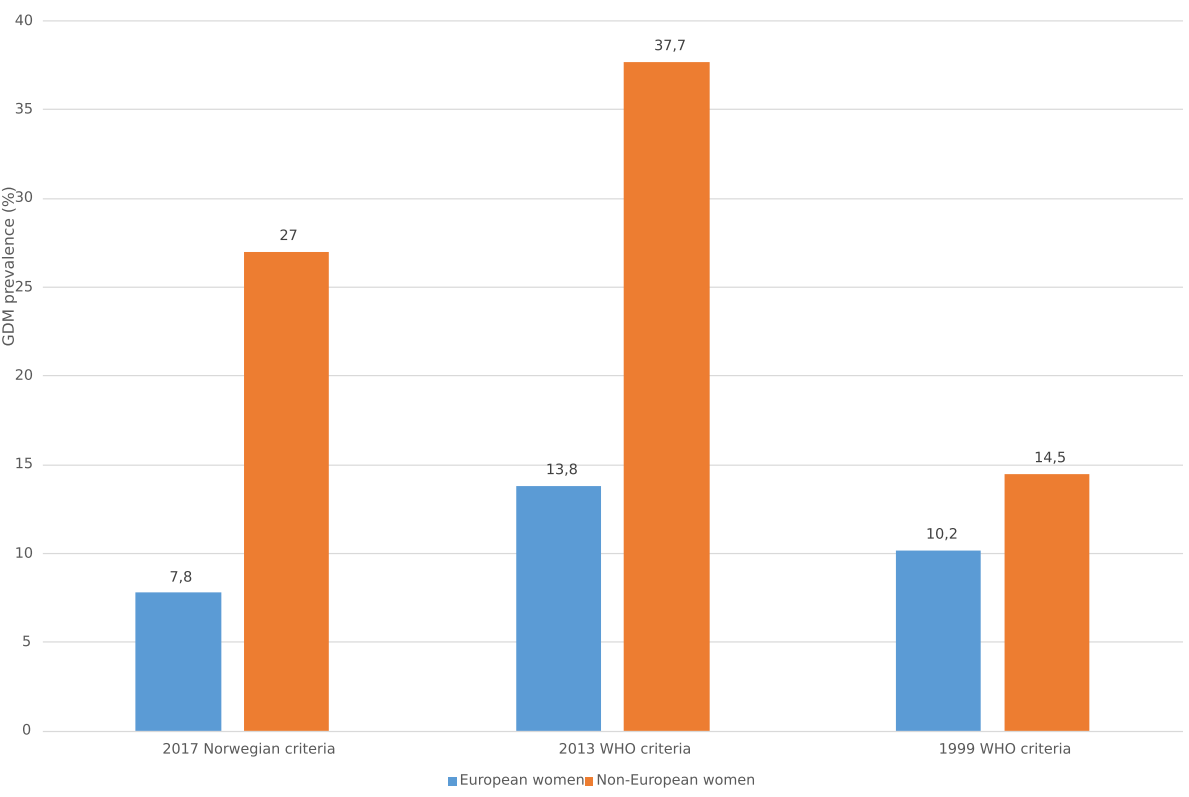

Fig. 2 GDM prevalence based on three diagnostic criteria ( 2017 Norwegian, $2013 \mathrm{WHO}$, 1999 WHO) for European and non-European women

\section{Discussion}

In this study of women universally offered an OGTT during the second half of pregnancy, we found a similar overall prevalence of GDM (10.7\% vs $10.3 \%)$ with the ${ }_{2017}$ Norwegian criteria and the previously used criteria ( $\left.{ }_{1999} \mathrm{WHO}\right)$, but using lower glucose level thresholds in line with ${ }_{2013}$ WHO criteria, identified considerably higher numbers of women with GDM (16.9\%). The prevalence more than doubled for non-European women applying the 2013 WHO and ${ }_{2017}$ Norwegian criteria, even after adjusting for covariates. Our study further shows that while advancing age and elevated BMI increased the risk of GDM, using these risk factors in pre-diagnostic screening is a poor method for accurately identifying women with GDM, resulting in many missed cases unless $70-80 \%$ of European women are tested. The sensitivity of the risk factors was lower for nonEuropean women, indicating an even stronger rationale for universal screening in these women.

Although shifting from the older ${ }_{1999} \mathrm{WHO}$ criteria to the new ${ }_{2017}$ Norwegian criteria resulted in a similar frequency of GDM, the groups identified differ in terms of their metabolic profile. The latter criteria identified more women with a higher prepregnancy BMI and non-European ethnicity, presumably attributable to the lower fasting glucose threshold.

Our prevalence rates applying the ${ }_{2013} \mathrm{WHO}$ criteria are comparable with estimates reported in other studies in the past decade, although differences in screening procedures, demographic characteristics of the subjects as well as the ethnic make-up of the population make direct comparisons complex. Guariguata et al. [15] estimated that the global prevalence of hyperglycaemia using the 2013 WHO criteria was $16.9 \%$. A more recent meta-analysis of high-income countries in Europe found an overall GDM prevalence of $5.4 \%$, regardless of diagnostic criteria used [16]. In contrast, a study using ${ }_{2013}$ WHO thresholds and only fasting glucose in a Danish pregnancy cohort, found that $40 \%$ were classified as having GDM [17]. The authors raised important questions about uniform application of diagnostic thresholds across the world, and suggested population-based local recommendations.

Multiple studies have evaluated selective risk factor-based strategies aiming to identify the best diagnostic approach for GDM [18, 19]. We demonstrate that the most sensitive and specific cut-offs for maternal age and BMI in European women were age $\geq 25$ years and $\mathrm{BMI} \geq 25 \mathrm{~kg} / \mathrm{m}^{2}$ when parity was added. However, used as a screening strategy this would mean inviting the majority of women for an OGTT as at least one of these risk factors applies to most women today. This confirms recent findings from a systematic review and meta-analysis by Farrar et al. [8] concluding that sensitivity increases with the number of women needing a test. This strategy does not vary much from universal screening, and supports the contention that identification of GDM requires testing of almost all pregnant women [20] 
Table 3 Associations between maternal risk factors and gestational diabetes mellitus in univariate analysis and multivariate analysis, applying the ${ }_{2017}$ Norwegian criteria

\begin{tabular}{|c|c|c|c|c|c|c|c|c|c|}
\hline \multirow[t]{2}{*}{ Variables } & \multicolumn{3}{|c|}{ Univariate analysis } & \multicolumn{3}{|c|}{ Model 1a: $r^{2}=0.158$} & \multicolumn{3}{|c|}{ Model $2^{\epsilon} r^{2}=0.157$} \\
\hline & Odds ratio & $95 \% \mathrm{Cl}$ & $P$-value & $\overline{\mathrm{aOR}}$ & $95 \% \mathrm{Cl}$ & $P$-value & $\overline{\mathrm{aOR}}$ & $95 \% \mathrm{Cl}$ & $P$-value \\
\hline Age (years) & & & 0.001 & & & 0.003 & & & 0.003 \\
\hline$\leq 25$ & 1 & & & 1 & & & 1 & & \\
\hline $25-29.9$ & 0.76 & $0.52-1.14$ & 0.191 & 0.90 & $0.57-1.41$ & 0.651 & 0.86 & $1.20-2.58$ & 0.495 \\
\hline $30-34.9$ & 0.82 & $0.55-0.21$ & 0.319 & 1.07 & $0.67-1.71$ & 0.768 & 1.00 & $0.64-1.56$ & 0.984 \\
\hline$\geq 35$ & 1.42 & $0.93-2.16$ & 0.100 & 1.84 & $1.10-3.07$ & 0.020 & 1.73 & $1.07-2.80$ & 0.026 \\
\hline Pre-pregnancy BMI $\left(\mathrm{kg} / \mathrm{m}^{2}\right)$ & & & $<0.001$ & & & $<0.001$ & & & $<0.001$ \\
\hline$\leq 25$ & 1 & & & 1 & & & 1 & & \\
\hline $25-26.9$ & 1.86 & $1.30-2.66$ & 0.001 & 1.76 & $1.20-2.57$ & 0.004 & 1.77 & $1.21-2.58$ & 0.003 \\
\hline $27-29.9$ & 2.73 & 1.89-3.95 & $<0.001$ & 2.60 & $1.75-3.87$ & $<0.001$ & 2.64 & $1.78-3.92$ & $<0.001$ \\
\hline$\geq 30$ & 5.97 & $4.31-8.26$ & $<0.001$ & 4.96 & $3.43-7.16$ & $<0.001$ & 5.12 & $3.56-7.35$ & $<0.001$ \\
\hline non-European ethnicity & 4.36 & $3.35-5.69$ & $<0.001$ & 2.46 & $1.53-3.94$ & $<0.001$ & 2.72 & $1.78-4.13$ & $<0.001$ \\
\hline Parous & 1.53 & $1.21-1.94$ & $<0.001$ & 0.99 & $0.73-1.34$ & 0.955 & & & \\
\hline Education & & & & & & 0.725 & & & \\
\hline Higher education & 1 & & & 1 & & & & & \\
\hline high school education & 2.07 & $1.59-2.71$ & $<0.001$ & 1.12 & $0.79-1.58$ & 0.504 & & & \\
\hline primary or less & 4.60 & $3.11-6.80$ & $<0.001$ & 1.21 & $0.69-2.09$ & 0.509 & & & \\
\hline Height (cm) & 0.95 & $0.93-0.96$ & $<0.001$ & 0.99 & $0.96-1.01$ & 0.341 & & & \\
\hline Current smoker & 1.66 & $0.89-3.11$ & 0.112 & 1.29 & $0.65-2.56$ & 0.454 & & & \\
\hline \multicolumn{10}{|l|}{ Cohort } \\
\hline Stork Rikshospitalet & 1 & & & & & & & & \\
\hline FFF & 0.77 & $0.52-1.15$ & 0.200 & & & & & & \\
\hline STORK Groruddalen & 2.70 & $2.03-3.57$ & $<0.001$ & & & & & & \\
\hline TRIP & 0.41 & $0.26-0.64$ & $<0.001$ & & & & & & \\
\hline Diabetes in family* & 1.88 & $1.40-2.53$ & $<0.001$ & & & & & & \\
\hline
\end{tabular}

Binary logistic regression was performed, 2017 Norway criteria

adjusted for age, pre-pregnancy BMI, ethnicity, parity, education, height, smoking and cohort (not shown)

${ }^{\epsilon}$ Adjusted for age, pre-pregnancy BMI, ethnicity and cohort (not shown)

Abbrevations: $a O R$ adjusted odds ratio, $\mathrm{Cl}$ confidens interval, $B M I$ body mass index

* Not measured in Fit for Delivery

especially considering the rise in maternal age and overweight/obesity among childbearing over recent years [21].

Selective screening has the potential to spare many pregnant women of diagnostic testing thereby reducing time and resource use. However, consistent with others $[22,23]$ we found that screening on the basis of risk factors would result in a larger number of missed diagnoses and hence limit the opportunity for immediate and long-term follow up and treatment. This is of concern, as a substantial proportion of women with GDM have no defined risk factors $[24,25]$. The importance of GDM management is now widely accepted, and evidence supports that treatment of even milder degrees of hyperglycaemia could improve pregnancy outcomes [26, 27].
Additionally, universal screening has the unique potential to identify this subset of women who would not otherwise be identified as having GDM, and, therefore, provide clinicians, as well as the women themselves, an opportunity to plan postpartum lifestyle interventions that could prevent or delay the onset of future type 2 diabetes [28-30].

Our study has several strengths. We merged data from four contemporary birth cohorts, allowing more powerful and flexible analyses. Additionally, although the level of missing was generally low, missing data were adequately handled by multiple imputation to prevent biased results. By including different geographical populations in Norway, we believe that the results may be broadly generalizable in Norway as well as to different antenatal 
Table 4 Associations between maternal risk factors and gestational diabetes mellitus in univariate analysis and multivariate analysis, applying the ${ }_{2013} \mathrm{WHO}$ criteria

\begin{tabular}{|c|c|c|c|c|c|c|c|c|c|}
\hline \multirow[t]{2}{*}{ Variables } & \multicolumn{3}{|c|}{ Univariate analysis } & \multicolumn{3}{|c|}{ Model $1^{\mathrm{a}}: \mathrm{r}^{2}=0.164$} & \multicolumn{3}{|c|}{ Model $2^{\epsilon} r^{2}=0.163$} \\
\hline & Odds ratio & $95 \% \mathrm{Cl}$ & $P$-value & aOR & $95 \% \mathrm{Cl}$ & $P$-value & aOR & $95 \% \mathrm{Cl}$ & $P$-value \\
\hline Age (years) & & & $<0.001$ & & & $<0.001$ & & & $<0.001$ \\
\hline$\leq 25$ & 1 & & & 1 & & & 1 & & \\
\hline $25-29.9$ & 0.74 & $0.53-1.01$ & 0.062 & 0.91 & $0.63-1.32$ & 0.622 & 0.87 & $0.60-1.25$ & 0.445 \\
\hline $30-34.9$ & 0.85 & $0.62-1.17$ & 0.321 & 1.24 & $0.84-1.83$ & 0.267 & 1.18 & $0.82-1.70$ & 0.381 \\
\hline$\geq 35$ & 1.50 & $1.07-2.13$ & 0.020 & 2.17 & $1.42-3.33$ & $<0.001$ & 2.07 & $1.38-3.09$ & $<0.001$ \\
\hline Pre-pregnancy BMI $\left(\mathrm{kg} / \mathrm{m}^{2}\right)$ & & & $<0.001$ & & & $<0.001$ & & & $<0.001$ \\
\hline$\leq 25$ & 1 & & & 1 & & & 1 & & \\
\hline $25-26.9$ & 1.84 & $1.38-2.46$ & $<0.001$ & 1.69 & $1.24-2.30$ & 0.001 & 1.70 & $1.25-2.32$ & $<0.001$ \\
\hline $27-29.9$ & 3.23 & $2.40-4.35$ & $<0.001$ & 2.96 & $2.15-4.09$ & $<0.001$ & 3.02 & $2.18-4.16$ & 0.001 \\
\hline$\geq 30$ & 4.84 & $3.60-6.49$ & $<0.001$ & 3.90 & $2.80-5.43$ & $<0.001$ & 4.06 & $2.93-5.61$ & $<0.001$ \\
\hline non-European ethnicity & 3.79 & $3.00-4.78$ & $<0.001$ & 1.91 & $1.28-2.86$ & 0.002 & 2.17 & $1.51-3.10$ & $<0.001$ \\
\hline Parous & 1.49 & $1.23-1.80$ & $<0.001$ & 1.02 & $0.79-1.31$ & 0.875 & & & \\
\hline Education & & & & & & 0.340 & & & \\
\hline Higher education & 1 & & & 1 & & & & & \\
\hline high school education & 1.89 & $1.52-2.36$ & $<0.001$ & 1.43 & $0.88-2.33$ & 0.148 & & & \\
\hline primary or less & 4.17 & $2.94-5.92$ & $<0.001$ & 1.11 & $0.84-1.47$ & 0.474 & & & \\
\hline Height & 0.96 & $0.94-0.97$ & $<0.001$ & 0.99 & $0.98-1.00$ & 0.580 & & & \\
\hline Current smoker & 0.65 & $0.38-1.12$ & 0.119 & 1.13 & $0.98-1.01$ & 0.674 & & & \\
\hline Cohort & & & $<0.001$ & & & & & & \\
\hline Stork Rikshospitalet & 1 & & & & & & & & \\
\hline FFF & 0.94 & $0.69-1.26$ & 0.668 & & & & & & \\
\hline STORK G & 2.64 & $2.09-3.34$ & $<0.001$ & & & & & & \\
\hline TRIP & 0.41 & $0.29-0.59$ & $<0.001$ & & & & & & \\
\hline Diabetes in family * & 1.85 & $1.44-2.38$ & $<0.001$ & & & & & & \\
\hline
\end{tabular}

Binary logistic regression was performed, $2013 \mathrm{WHO}$-criteria. ${ }^{\mathrm{a}}$ Adjusted for age, pre-pregnancy BMl, ethnicity, parity, education, height, smoking and cohort (not shown). ${ }^{\epsilon}$ Adjusted for age, pre-pregnancy BMI, ethnicity and cohort (not shown)

Abbrevations: $a O R$ adjusted odds ratio, $C l$ confidens interval, $B M I$ body mass index

* Not measured in Fit for Delivery

populations in other high-income countries. Moreover, our study included women from various ethnic groups, making our findings relevant to other European countries with similar immigrant populations. It is of note, however, that almost all non-European women came from one study and more than half were of Asian (mainly South Asian) origin. Nevertheless, the proportion included and the composition of this group, is representative for the pregnant population with non-European ethnicity living in Norway [31].

The majority of the European women in our study had a normal BMI and high educational level, which may indicate that our prevalence rates of GDM are less generalizable to more high-risk populations. The rates of overweight and obesity in our cohort were somewhat lower than our background population
( $8 \%$ obesity in our study vs $12 \%$ nationally in 2018 ) [32]. A selection bias towards inclusion of individuals with a higher health awareness, as is often seen in clinical studies, may have led to underestimation of the reported prevalence rates and the numbers needed to be screened. A higher proportion of overweight/obesity would require an OGTT of a larger number of women. In addition, had a 1-h value been measured in our study, the prevalence of GDM by the ${ }_{2013}$ WHO criteria would presumably have increased somewhat. Second, two of the included studies were RCT's with a lifestyle intervention for half of the women. However, no effect of the intervention on GDM status was reported in these studies and, reassuringly, our findings remained unchanged in sensitivity analyses. Lastly, we present data from four cohorts pooled into one data set where each study 
Table 5 Performance of risk factors, alone or in combination, for the identification of GDM, with two criteria (2017 Norwegian and 2013 WHO)

\section{Norwegian criteria}

\section{Risk factors}

European background, $n=2588$

\begin{tabular}{|c|}
\hline $\mathrm{BMI} \geq 25 \mathrm{~kg} / \mathrm{m}^{2}$ \\
\hline $\mathrm{BMI} \geq 27 \mathrm{~kg} / \mathrm{m}^{2}$ \\
\hline $\mathrm{BMI} \geq 30 \mathrm{~kg} / \mathrm{m}^{2}$ \\
\hline Age $\geq 25$ years \\
\hline Age $\geq 30$ years \\
\hline Age $\geq 25$ or $\mathrm{BMI} \geq 25$ \\
\hline Age $\geq 30$ or $\mathrm{BMI} \geq 30$ \\
\hline Age $\geq 30$ or $\mathrm{BMI} \geq 27$ \\
\hline $\begin{array}{l}\mathrm{BMI} \geq 25 \text { or (Primipara }+ \text { Age } \geq 25 \text { ) or (parous }+ \\
\text { age } \geq 35 \text { ) }\end{array}$ \\
\hline $\begin{array}{l}\mathrm{BMI} \geq 25 \text { or (Primipara }+ \text { Age } \geq 25 \text { ) or (parous }+ \\
\text { age } \geq 40 \text { ) }\end{array}$ \\
\hline $\begin{array}{l}\mathrm{BMI} \geq 25 \text { or (Primipara }+ \text { Age } \geq 30 \text { ) or (parous }+ \\
\text { age } \geq 35 \text { ) }\end{array}$ \\
\hline $\begin{array}{l}\mathrm{BMI} \geq 27 \text { or (Primipara }+ \text { Age } \geq 30 \text { ) or (parous }+ \\
\text { age } \geq 35 \text { ) }\end{array}$ \\
\hline Family history of diabetes* \\
\hline $\mathrm{BMI} \geq 25$ or Age $\geq 30$ or family history of diabetes \\
\hline Non-European background, $n=393$ \\
\hline $\mathrm{BMI} \geq 23 \mathrm{~kg} / \mathrm{m}^{2}$ \\
\hline $\mathrm{BMI} \geq 25 \mathrm{~kg} / \mathrm{m}^{2}$ \\
\hline $\mathrm{BMI} \geq 27 \mathrm{~kg} / \mathrm{m}^{2}$ \\
\hline Age $\geq 25$ years \\
\hline Age $\geq 30$ years \\
\hline Age $\geq 25$ or $\mathrm{BMI} \geq 25$ \\
\hline Age $\geq 30$ or $\mathrm{BMI} \geq 23$ \\
\hline $\begin{array}{l}\mathrm{BMI} \geq 25 \text { or (Primipara }+ \text { Age } \geq 25 \text { ) or (parous }+ \\
\text { age } \geq 35 \text { ) }\end{array}$ \\
\hline Family history of diabetes* \\
\hline
\end{tabular}

\section{WHO criteria}

\section{Risk factors}

European background, $\boldsymbol{n}=\mathbf{2 5 8 8}$

$\mathrm{BMI} \geq 25 \mathrm{~kg} / \mathrm{m}^{2}$
$\mathrm{BMI} \geq 27 \mathrm{~kg} / \mathrm{m}^{2}$
$\mathrm{BMI} \geq 30 \mathrm{~kg} / \mathrm{m}^{2}$
Age $\geq 25$ years
Age $\geq 30$ years
Age $\geq 25$ or $\mathrm{BMI} \geq 25$
Age $\geq 30$ or $\mathrm{BMI} \geq 30$
Age $\geq 30$ or BMI $\geq 27$
$\mathrm{BMI} \geq 25$ or (Primipara + Age $\geq 25$ ) or (parous +
age $\geq 35$ )

\begin{tabular}{|c|c|c|c|c|c|}
\hline $\begin{array}{l}\text { Sensitivity } \\
\text { (\%) }\end{array}$ & $\begin{array}{l}\text { Specificity } \\
(\%)\end{array}$ & $\begin{array}{l}\text { PPV } \\
\text { (\%) }\end{array}$ & $\begin{array}{l}\text { NPV } \\
(\%)\end{array}$ & $\begin{array}{l}\text { OGTT's needed } \\
\text { (\%) }\end{array}$ & $\begin{array}{l}\text { Undetected GDM cases } \\
(\%)\end{array}$ \\
\hline 53.0 & 75.6 & 15.5 & 95 & 26.6 & 47.0 \\
\hline 36.6 & 87 & 19.2 & 94.2 & 14.9 & 63.4 \\
\hline 22.8 & 94.4 & 24.4 & 93.9 & 6.8 & 77.7 \\
\hline 91.1 & 10.1 & 7.9 & 93.1 & 90.0 & 8.9 \\
\hline 60.4 & 45.5 & 8.6 & 93.1 & 54.9 & 39.6 \\
\hline 96.5 & 7.2 & 8.1 & 96.1 & 93.1 & 3.5 \\
\hline 71.3 & 42.7 & 9.5 & 94.6 & 58.4 & 28.7 \\
\hline 74.3 & 39.4 & 9.4 & 94.8 & 61.6 & 25.7 \\
\hline 85.1 & 26.0 & 8.9 & 95.4 & 74.9 & 14.9 \\
\hline 78.7 & 32.3 & 9.0 & 94.7 & 68.5 & 21.3 \\
\hline 72.8 & 47.9 & 10.6 & 95.4 & 53.7 & 27.2 \\
\hline 61.9 & 54.5 & 10.3 & 94.4 & 46.8 & 38.1 \\
\hline 11.5 & 89.1 & 8.7 & 92.1 & 10.6 & 87.3 \\
\hline 87.8 & 22.8 & 9.3 & 95.4 & 78.1 & 12.2 \\
\hline 64.2 & 46.0 & 30.5 & 77.6 & 56.7 & 35.8 \\
\hline 47.2 & 66.2 & 34.0 & 77.2 & 37.4 & 52.8 \\
\hline 37.7 & 80.5 & 41.7 & 77.8 & 24.4 & 62.3 \\
\hline 80.2 & 23.3 & 27.9 & 76.1 & 77.6 & 19.8 \\
\hline 50.0 & 63.4 & 33.5 & 77.4 & 40.2 & 50.0 \\
\hline 87.7 & 17.4 & 28.2 & 79.4 & 84.0 & 12.3 \\
\hline 74.5 & 33.1 & 29.2 & 77.9 & 69.0 & 25.5 \\
\hline 69.8 & 42.5 & 31.0 & 79.2 & 60.8 & 30.2 \\
\hline 42.6 & 64.3 & 30.3 & 75.4 & 37.6 & 57.4 \\
\hline $\begin{array}{l}\text { Sensitivity } \\
\text { (\%) }\end{array}$ & $\begin{array}{l}\text { Specificity } \\
(\%)\end{array}$ & $\begin{array}{l}\text { PPV } \\
\text { (\%) }\end{array}$ & $\begin{array}{l}\text { NPV } \\
\text { (\%) }\end{array}$ & $\begin{array}{l}\text { OGTT's needed } \\
(\%)\end{array}$ & $\begin{array}{l}\text { Undetected GDM cases } \\
\text { (\%) }\end{array}$ \\
\hline 48.3 & 76.8 & 25.0 & 90.3 & 26.6 & 51.7 \\
\hline 33.2 & 87.9 & 29.5 & 89.7 & 14.9 & 66.8 \\
\hline 16.6 & 94.8 & 33.7 & 87.7 & 6.8 & 83.4 \\
\hline 90.4 & 10.1 & 13.8 & 86.9 & 90.0 & 9.6 \\
\hline 62.1 & 46.2 & 15.5 & 88.4 & 54.9 & 37.9 \\
\hline 95.2 & 7.2 & 14.1 & 90.4 & 93.1 & 4.8 \\
\hline 69.7 & 43.4 & 16.4 & 90.0 & 58.4 & 30.3 \\
\hline 75.0 & 40.5 & 16.7 & 91.0 & 61.6 & 25.0 \\
\hline 83.1 & 26.4 & 15.3 & 90.8 & 74.9 & 16.9 \\
\hline
\end{tabular}


Table 5 Performance of risk factors, alone or in combination, for the identification of GDM, with two criteria (2017 Norwegian and $2013 \mathrm{WHO}$ ) (Continued)

\begin{tabular}{|c|c|c|c|c|c|c|}
\hline $\begin{array}{l}\text { BMI } \geq 25 \text { or (Primipara }+ \text { Age } \geq 25 \text { ) or (parous }+ \\
\text { age } \geq 40 \text { ) }\end{array}$ & 76.4 & 32.7 & 15.3 & 89.7 & 68.5 & 23.6 \\
\hline $\begin{array}{l}\mathrm{BMI} \geq 25 \text { or (Primipara }+ \text { Age } \geq 30 \text { ) or (parous }+ \\
\text { age } \geq 35 \text { ) }\end{array}$ & 71.1 & 49.1 & 18.2 & 91.4 & 53.7 & 28.9 \\
\hline $\begin{array}{l}\mathrm{BMI} \geq 27 \text { or (Primipara }+ \text { Age } \geq 30 \text { ) or (parous }+ \\
\text { age } \geq 35 \text { ) }\end{array}$ & 62.9 & 55.8 & 18.5 & 90.4 & 46.8 & 37.1 \\
\hline Family history of diabetes* & 13.2 & 89.5 & 17.3 & 86.6 & 10.6 & 86.8 \\
\hline $\mathrm{BMI} \geq 25$ or Age $\geq 30$ or family history of diabetes & 87.5 & 23.5 & 16.2 & 91.8 & 78.1 & 12.5 \\
\hline \multicolumn{7}{|l|}{ Non-European background, $n=393$} \\
\hline $\mathrm{BMI} \geq 23 \mathrm{~kg} / \mathrm{m}^{2}$ & 66.2 & 49.0 & 43.9 & 70.6 & 56.7 & 33.8 \\
\hline $\mathrm{BMI} \geq 25 \mathrm{~kg} / \mathrm{m}^{2}$ & 47.3 & 68.6 & 47.6 & 68.3 & 37.4 & 52.7 \\
\hline $\mathrm{BMI} \geq 27 \mathrm{~kg} / \mathrm{m}^{2}$ & 36.5 & 89.2 & 56.3 & 68.4 & 24.4 & 63.5 \\
\hline Age $\geq 25$ years & 80.4 & 24.1 & 39.0 & 67.0 & 77.6 & 19.6 \\
\hline Age $\geq 30$ years & 48.0 & 64.5 & 44.9 & 67.2 & 40.2 & 52.0 \\
\hline Age $\geq 25$ or $\mathrm{BMI} \geq 25$ & 87.8 & 18.4 & 39.4 & 71.4 & 84.0 & 12.2 \\
\hline Age $\geq 30$ or $\mathrm{BMI} \geq 23$ & 76.4 & 35.5 & 41.7 & 71.3 & 69.0 & 23.6 \\
\hline $\begin{array}{l}\mathrm{BMI} \geq 25 \text { or (Primipara }+ \text { Age } \geq 25 \text { ) or (parous }+ \\
\text { age } \geq 35 \text { ) }\end{array}$ & 69.6 & 44.5 & 43.1 & 70.8 & 60.8 & 30.4 \\
\hline Family history of diabetes* & 40.1 & 64.0 & 40.1 & 64.0 & 37.6 & 59.9 \\
\hline
\end{tabular}

Abbrevations: BMI body mass index, WHO World Health Organization, PPV positive predictive value, NPV negative predictive value, OGTT oral glucose tolerance test, GDM gestational diabetes

*Family history of diabetes was not measured in Fit for Delivery

differs somewhat in terms of inclusion period, time of OGTT and geography, although by including Norwegian studies only and adjusting for study cohort this source of heterogeneity was limited.

\section{Conclusion}

The use of a stricter diagnostic criteria than the ${ }_{2013} \mathrm{WHO}$ (OR of 2.0 vs. 1.75) limited the prevalence of GDM to approximately the same level as the older ${ }_{1999}$ WHO. We found that maternal characteristics are of limited use in identifying women with GDM, requiring testing of almost all women to avoid overlooking a substantial number of cases. The costs and benefits of universal screening, and the use of alternative testing algorithms or biomarkers, require further evaluation.

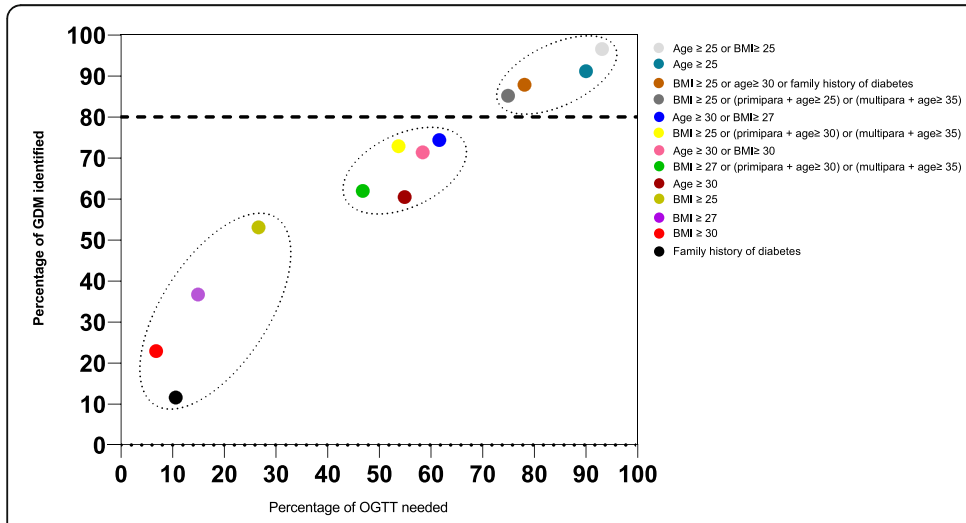

a) Based on 2017 Norway criteria

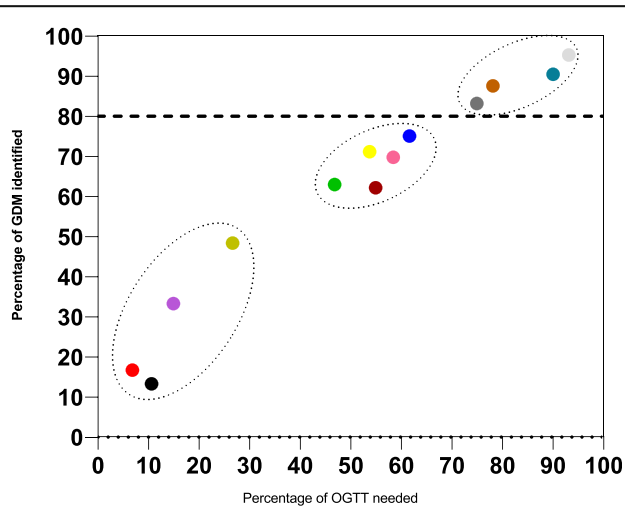

b) Based on 2013 WHO criteria

Fig. 3 Screening performance (sensitivity and percentage offered an OGTT) of risk factors (single or in combinations) for European women with the ${ }_{2017}$ Norwegian criteria (a) and ${ }_{2013}$ WHO criteria (b). The color of the points indicates the risk factors used, and the line indicates $80 \%$ sensitivity. The clusters indicate poor (bottom left corner), moderate and good performance (top right corner) 


\section{Abbreviations}

BMl: Body mass index; GDM: Gestational diabetes mellitus; OGT: Oral glucose tolerance test; OR: Odds ratio; WHO: World Health Organization

\section{Supplementary Information}

The online version contains supplementary material available at https://doi. org/10.1186/s12884-021-04086-9.

Additional file 1. : Supporting information Table S1. Characteristics of study participants according to their glucose tolerance status, with three criteria (1999 WHO, 2013 WHO and ${ }_{2017}$ Norwegian criteria). Supporting information Table S2. Associations between maternal risk factors and gestational diabetes mellitus in univariate analysis and multivariate analysis, using the ${ }_{1999} \mathrm{WHO}$ criteria.

\section{Acknowledgements}

The authors would like to thank the following members of the Norwegian Hyperglycemia in Pregnancy consortium: Elisabeth Qvigstad (University of Oslo, Oslo, Norway) and Marie Cecilie Paasche-Roland (Oslo University Hospital-Rikshospitalet, Oslo, Norway) for their contribution in the STORK Rikshospitalet study, Siv Mørkved (Norwegian University of Science and Technology, Trondheim, Norway) for her contribution in the TRIP study, and Ingvild Vistad (University of Bergen, Bergen, Norway) for her contribution in the Fit for Delivery study.

\section{Authors' contributions}

The original data was collected by AKJ, LS, LRS, SNS and TL. AKJ conceived and designed this study and LS, NC $\varnothing$ and LRS participated in the planning of the project. They also participated in the interpretation of data, the writing process and reviewing the manuscript. ASR analyzed the data and wrote the manuscript under supervision. AHP assisted in the planning and performing of statistical analyses. All authors have read and approved the final version.

\section{Funding}

This work was funded by South-Eastern Norway Regional Health Authority. The funder was not involved in the design of the study, data collection, analyses or interpretation of data, nor the writing of the manuscript.

\section{Availability of data and materials}

The datasets generated and/or analyzed during the current study are not publicly available due to the dataset containing clinical data which cannot be shared publicly, and as the study is part of a PhD work. The data are available from the corresponding author on reasonable request.

\section{Declarations}

\section{Ethics approval and consent to participate}

Written informed consent was obtained from all the participants in the original studies. Norwegian Regional Ethics committees (REC) approved that each constituent study could contribute to the consortium, and the current study was approved by the REC South East (2017/2533). All methods were performed in accordance with the relevant guidelines and regulations. Privacy and confidentiality were maintained throughout the study.

\section{Consent for publication}

Not applicable.

\section{Competing interests}

The authors declare that they have no competing interests.

\section{Author details}

'Department of Research, Sorlandet Hospital, 4604 Kristiansand, Norway. ${ }^{2}$ Department of Pediatric and Adolescents Medicine, Akershus University Hospital, Akershus, Norway. ${ }^{3}$ Institute of Clinical Medicine, University of Oslo, Oslo, Norway. ${ }^{4}$ Department of General Medicine, General Practice Research Unit (AFE), Institute of Health and Society, University of Oslo, Oslo, Norway. ${ }^{5}$ Department of Nutrition and Public Health, Faculty of Health and Sport Sciences, University of Agder, Kristiansand, Norway. ${ }^{6}$ Department of Public
Health and Nursing, Norwegian University of Science and Technology (NTNU), Trondheim, Norway. 'Department of Clinical Services, St.Olavs Hospital Trondheim University Hospital, Trondheim, Norway. ${ }^{8}$ Research Institute of Internal Medicine, Oslo University Hospital, Oslo, Norway. ${ }^{9}$ Oslo Centre of Biostatistics and Epidemiology, Research Support Services, Oslo University Hospital, Oslo, Norway. ${ }^{10}$ Department of Obstetrics and Gynaecology, Sorlandet Hospital, Kristiansand, Norway.

Received: 31 March 2021 Accepted: 29 August 2021

Published online: 08 September 2021

\section{References}

1. American Diabetes Association. 2. Classification and diagnosis of diabetes: standards of medical Care in Diabetes-2018. Diabetes Care. 2018; 41(Supplement 1):S13-27.

2. Song C, Lyu Y, Li C, Liu P, Li J, Ma RC, et al. Long-term risk of diabetes in women at varying durations after gestational diabetes: a systematic review and meta-analysis with more than 2 million women. Obes Rev. 2018;19(3): 421-9. https://doi.org/10.1111/obr.12645.

3. Crowther CA, Hiller JE, Moss JR, McPhee AJ, Jeffries WS, Robinson JS, et al. Effect of treatment of gestational diabetes mellitus on pregnancy outcomes. New Engl J Med. 2005;352(24):2477-86. https://doi.org/10.1056/NEJMoa042 973.

4. Benhalima K, Mathieu C, Assche A, Damm P, Devlieger R, Mahmood T, et al. Survey by the European board and College of Obstetrics and Gynaecology on screening for gestational diabetes in Europe. Eur J Obstet Gynecol Reprod Biol. 2016;201:197-202. https://doi.org/10.1016/j.ejogrb.2016.04.003.

5. Metzger BE, Lowe LP, Dyer AR, Trimble ER, Chaovarindr U, Coustan DR, et al. Hyperglycemia and adverse pregnancy outcomes. N Engl J Med. 2008; 358(19):1991-2002. https://doi.org/10.1056/NEJMoa0707943.

6. Cundy T, Ackermann E, Ryan EA. Gestational diabetes: new criteria may triple the prevalence but effect on outcomes is unclear. BMJ. 2014; 348(mar11 6):g1567. https://doi.org/10.1136/bmj.g1567.

7. Marozio L, Picardo E, Filippini C, Mainolfi E, Berchialla P, Cavallo F, et al. Maternal age over 40 years and pregnancy outcome: a hospital-based survey. J Matern Fetal Neonatal Med. 2019;32(10):1602-8. https://doi.org/1 $0.1080 / 14767058.2017 .1410793$

8. Farrar D, Simmonds M, Bryant M, Lawlor DA, Dunne F, Tuffnell D, et al. Risk factor screening to identify women requiring oral glucose tolerance testing to diagnose gestational diabetes: a systematic review and meta-analysis and analysis of two pregnancy cohorts. PLoS One. 2017;12(4):e0175288. https:// doi.org/10.1371/journal.pone.0175288.

9. Jenum AK, Sletner L, Voldner N, Vangen S, Mørkrid K, Andersen LF, et al. The STORK Groruddalen research programme: a population-based cohort study of gestational diabetes, physical activity, and obesity in pregnancy in a multiethnic population. Rationale, methods, study population, and participation rates. Scand J Public Health. 2010;38(5 Suppl):60-70. https:// doi.org/10.1177/1403494810378921.

10. Frøslie KF, Røislien J, Qvigstad E, Godang K, Bollerslev J, Voldner N, et al. Shape information from glucose curves: functional data analysis compared with traditional summary measures. BMC Med Res Methodol. 2013;13:6.

11. Sagedal LR, Øverby NC, Lohne-Seiler H, Bere E, Torstveit MK, Henriksen T, et al. Study protocol: fit for delivery - can a lifestyle intervention in pregnancy result in measurable health benefits for mothers and newborns? A randomized controlled trial. BMC Public Health. 2013;13(1):132. https://doi. org/10.1186/1471-2458-13-132.

12. Stafne SN, Salvesen KÅ, Romundstad PR, Eggebø TM, Carlsen SM, Mørkved S. Regular exercise during pregnancy to prevent gestational diabetes: a randomized controlled trial. Obstet Gynecol. 2012;119(1):29-36. https://doi. org/10.1097/AOG.0b013e3182393f86.

13. Van Buuren S. Flexible imputation of missing data. 2nd ed. Boca Raton: Chapman and Hall/CRC; 2018. https://doi.org/10.1201/9780429492259.

14. Steyerberg EW. Clinical prediction models. New York: Springer-Verlag New York; 2009. https://doi.org/10.1007/978-0-387-77244-8.

15. Guariguata L, Linnenkamp U, Beagley J, Whiting DR, Cho NH. Global estimates of the prevalence of hyperglycaemia in pregnancy. Diabetes Res Clin Pract. 2014:103(2):176-85. https://doi.org/10.1016/j.diabres.2013.11.003.

16. Eades CE, Cameron DM, Evans JMM. Prevalence of gestational diabetes mellitus in Europe: a meta-analysis. Diabetes Res Clin Pract. 2017;129:173-81. https://doi.org/10.1016/j.diabres.2017.03.030. 
17. Mclntyre HD, Jensen $D M$, Jensen $R C$, Kyhl HB, Jensen $T K$, Glintborg $D$, et al. Gestational diabetes mellitus: does one size fit all? A challenge to uniform worldwide diagnostic thresholds. Diabetes Care. 2018;41(7):1339-42. https:// doi.org/10.2337/dc17-2393.

18. Pintaudi B, Di Vieste G, Corrado F, Lucisano G, Pellegrini F, Giunta L, et al. Improvement of selective screening strategy for gestational diabetes through a more accurate definition of high-risk groups. Eur J Endocrinol. 2014;170(1):87-93. https://doi.org/10.1530/EJE-13-0759.

19. Benhalima K, Damm P, Van Assche A, Mathieu C, Devlieger R, Mahmood T, et al. Screening for gestational diabetes in Europe: where do we stand and how to move forward?: a scientific paper commissioned by the European board \&amp; College of Obstetrics and Gynaecology (EBCOG). Eur J Obstet Gynecol Reprod Biol. 2016;201:192-6. https://doi.org/10.1016/j.ejogrb.2016. 04.002 .

20. Hod M, Kapur A, Sacks DA, Hadar E, Agarwal M, Di Renzo GC, et al. The International Federation of Gynecology and Obstetrics (FIGO) initiative on gestational diabetes mellitus: a pragmatic guide for diagnosis, management, and care. Int J Gynaecol Obstet. 2015;131(Suppl 3):S173-211. https://doi. org/10.1016/50020-7292(15)30033-3.

21. Matthews TJ, Hamilton BE. First births to older women continue to rise. NCHS Data Brief. 2014;152:1-8.

22. Zhou Q, Wang Q, Shen H, Zhang Y, Zhang S, Li X. Prevalence of diabetes and regional differences in Chinese women planning pregnancy: a Nationwide population-based cross-sectional study. Diabetes Care. 2017; 40(2):e16-e8. https://doi.org/10.2337/dc16-2188.

23. Cosson E, Cussac-Pillegand C, Benbara A, Pharisien I, Jaber Y, Banu I, et al. The diagnostic and prognostic performance of a selective screening strategy for gestational diabetes mellitus according to ethnicity in Europe. I Clin Endocrinol Metab. 2014;99(3):996-1005. https://doi.org/10.1210/jc.2013-3383.

24. Avalos GE, Owens LA, Dunne F, Collaborators AD. Applying current screening tools for gestational diabetes mellitus to a European population: is it time for change? Diabetes Care. 2013;36(10):3040-4. https://doi.org/1 $0.2337 / \mathrm{dc} 12-2669$

25. Arora D, Arora R, Sangthong S, Leelaporn W, Sangratanathongchai J. Universal screening of gestational diabetes mellitus: prevalence and diagnostic value of clinical risk factors. J Med Assoc Thail. 2013;96(3):266-71.

26. Landon MB, Spong CY, Thom E, Carpenter MW, Ramin SM, Casey B, et al. A multicenter, randomized trial of treatment for mild gestational diabetes. Obstet Anesth Dig. 2010;30(4):232. https://doi.org/10.1097/01.aoa.0000389610.71133.ee.

27. Hartling L, Dryden DM, Guthrie A, Muise M, Vandermeer B, Donovan L. Benefits and harms of treating gestational diabetes mellitus: a systematic review and meta-analysis for the U.S. preventive services task force and the National Institutes of Health Office of medical applications of research. Ann Intern Med. 2013;159(2):123-9. https://doi.org/10.7326/0003-4819-159-2-2 01307160-00661

28. Xin Y, Davies A, McCombie L, Briggs A, Messow CM, Grieve E, et al. Withintrial cost and 1-year cost-effectiveness of the DiRECT/counterweight-plus weight-management programme to achieve remission of type 2 diabetes. Lancet Diabetes Endocrinol. 2019;7(3):169-72. https://doi.org/10.1016/S22138587(18)30346-2.

29. Aroda VR, Christophi CA, Edelstein SL, Zhang P, Herman WH, Barrett-Connor $E$, et al. The effect of lifestyle intervention and metformin on preventing or delaying diabetes among women with and without gestational diabetes: the diabetes prevention program outcomes study 10-year follow-up. J Clin Endocrinol Metab. 2015;100(4):1646-53. https://doi.org/10.1210/jc.2014-3761.

30. Bao W, Tobias DK, Bowers K, Chavarro J, Vaag A, Grunnet LG, et al. Physical activity and sedentary behaviors associated with risk of progression from gestational diabetes mellitus to type 2 diabetes mellitus: a prospective cohort study. JAMA Intern Med. 2014;174(7):1047-55. https://doi.org/10.1 001/jamainternmed.2014.1795.

31. Norwegian Institute of Public Health The Medical Birth Registry of Norway statistics. F18a: Mors fødeland, 2018, [Mothers country of birth]. Available online at: http://statistikkbank.fhi.no/mfr/ (Accessed 10th May 2021).

32. Norwegian Institute of Public Health The Medical Birth Registry of Norway statistics. F18a: Mors kroppsmasseindeks før svangerskapet, 2018 [Mothers body mass index pre pregnancy]. Available online at: http://statistikkbank.fhi. no/mfr/ (Accessed 3 Jan 2021)

\section{Publisher's Note}

Springer Nature remains neutral with regard to jurisdictional claims in published maps and institutional affiliations.

Ready to submit your research? Choose BMC and benefit from:

- fast, convenient online submission

- thorough peer review by experienced researchers in your field

- rapid publication on acceptance

- support for research data, including large and complex data types

- gold Open Access which fosters wider collaboration and increased citations

- maximum visibility for your research: over $100 \mathrm{M}$ website views per year

At BMC, research is always in progress.

Learn more biomedcentral.com/submissions 